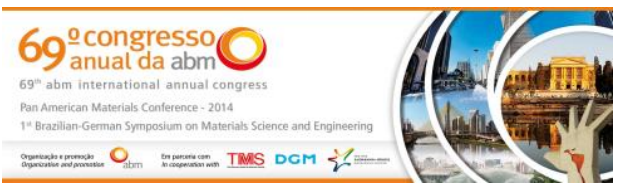

Tema: Tratamento Térmico

\title{
ESTUDO DA ADIÇÃO DE ETANOL AO GÁS NATURAL NA CEMENTAÇÃO DO AÇO DIN 17NICRMO5 NA FABRICAÇÃO DE ENGRENAGENS*
}

\author{
Rogério Pinto Coelho Catalão ${ }^{1}$ \\ Omar Kayyam Ribas ${ }^{2}$ \\ André França Bragança ${ }^{3}$ \\ José Rubens Gonçalves Carneiro ${ }^{4}$ \\ Pedro Paiva Brito
}

\section{Resumo}

No presente trabalho utilizou-se etanol no tratamento de cementação de engrenagens de aço DIN17NiCrMo5 utilizadas em transmissões automotivas. O processo de cementação foi realizado em fornos industriais contínuos utilizando gás natural e etanol como agentes cementantes às temperaturas de $870^{\circ} \mathrm{C}, 890^{\circ} \mathrm{C}$ e $930^{\circ} \mathrm{C}$ após o qual as peças foram temperadas e revenidas. As amostras tratadas foram submetidas à análise de fases por difração de raios- $X$ e as microestruturas foram caracterizadas por microscopia ótica. O tamanho de grão austenítico das amostras tratadas foi determinado em $20 \pm 2 \mu \mathrm{m}$ com percentual de austenita retida entre $20 \%$ e $30 \%$. A adição de etanol elevou o teor de CO na atmosfera do forno. Foi determinada a variação do teor de carbono em profundidade nas amostras tratadas, o que permitiu o cálculo das constantes de difusão do carbono na austenita.

Palavras-chave: Cementação; Etanol; Austenita retida; Difusão.

\section{CARBURIZING OF DIN 17NICRMO5 STEEL GEARS IN NATURAL GAS AND ETHANOL ATMOSPHERE}

\section{Abstract}

In the present work DIN 17NiCrMo5 steel gears used in automotive transmission systems were submitted to a carburizing thermo-chemical treatment. The carburizing process was carried out in industrial furnaces with controlled atmospheres of ethanol and natural gas at temperatures of $870^{\circ} \mathrm{C}, 890^{\circ} \mathrm{C}$ and $930^{\circ} \mathrm{C}$. After the carburizing, the samples were submitted phase analysis by X-ray diffraction and the depth resolved carbon concentration gradients were determined. Microstructure characterization was performed by applying optical and scanning electron microscopy. Residual austenite was detected in the amounts of $20 \%-30 \%$ with an average grain size of $20 \pm 2 \mu \mathrm{m}$. The addition of ethanol allowed for CO enrichment in the furnace atmosphere. The diffusion constants of carbon in austenite could be determined.

Keywords: Carburizing; Ethanol; Retained austenite; Diffusion.

1 Estudante de Pós-Graduação em Engenharia Mecânica, PUC-MG, Tecnólogo de Processos, Fiat Powertrain, Betim, MG, Brasil.

2 Estudante de Pós-Graduação em Engenharia Mecânica, PUC-MG, Tecnólogo de Processos, Fiat Powertrain, Betim, MG, Brasil.

3 Estudante de Pós-Graduação em Engenharia Mecânica, CEFET-MG, Belo Horizonte, MG, Brasil.

4 Dr. Msc., Engenheiro Mecânico, Professor Adjunto IV, Departamento de Engenharia Mecânica, Pontifícia Universidade Católica de Minas Gerais, MG, Brasil.

5 Dr.-Ing. Msc., Engenheiro Mecânico, Professor Adjunto IV, Departamento de Engenharia Mecânica, Pontifícia Universidade Católica de Minas Gerais, MG, Brasil.


Nacional de Estudantes de Engenharia Metalúrgica, de Materiais e de Minas, 21 a 25 de julho de 2014, São Paulo, SP, Brasil.
} 


\section{INTRODUÇÃO}

A indústria automobilística passa por um processo de mudança em decorrência da inovação tecnológica em seus processos e gestão. A intensificação da concorrência, pressões econômicas, legislativas e ambientais impostas pelo governo e sociedade levaram à busca por produtos ecologicamente corretos, duráveis e de baixo custo. Inserem-se nesse contexto as transmissões manuais e automáticas, responsáveis pela transferência da potência desenvolvida no motor para as rodas. A expectativa de vida de sistemas mecânicos depende dos componentes mais críticos desse sistema, que, no caso das transmissões, são as engrenagens.

O aumento da vida útil de engrenagens em sistemas de transmissão automotivos pode ser alcançado mediante a aplicação de técnicas de modificação superficial, por meio das quais se podem elevar a resistência mecânica, à corrosão e ao desgaste dos componentes além de criar efeito de barreira térmica. Os problemas relacionados com a fadiga, que é o principal mecanismo de falha de componentes de máquina tais como engrenagens e eixos, também podem ser mitigados com tratamentos mecânicos e termoquímicos de modificação de superfície. Particularmente, os materiais suscetíveis à transformação causada por deformação têm atraído atenção dos pesquisadores devido às possibilidades aumento da taxa de encruamento e extensão da faixa de alongamento uniforme [1].

Dentre os tratamentos termoquímicos e mecânicos mais importantes, incluem-se a cementação, nitretação, cianetação, carbonitretação, "shot peening" e impacto por cavitação de água [2,3]. Os tratamentos termoquímicos alteram a composição química superficial do aço, e podem ser seguidos ou precedidos de tratamento térmico adequado. Há diversos métodos de endurecimento superficial dos aços em escala industrial com a finalidade de possibilitar ganho na resistência ao desgaste e à fadiga, dentre eles cementação a gás ou líquida, a vácuo e a plasma, seguidos de têmpera e revenimento. A cementação gasosa é aplicada na indústria automobilística em razão de produção de volumes elevados [4].

A cementação é uma das técnicas mais utilizadas para aumentar a resistência ao desgaste superficial de componentes de máquina submetidos à fadiga por flexão e de contato por introduzir tensões residuais compressivas na superfície e subsuperfície. Em trabalho, essas tensões residuais se opõem às tensões originárias das cargas externas aplicadas e melhoram o desempenho do componente [5]. No tratamento térmico, especialmente na cementação seguida de têmpera, mudanças na microestrutura, geração de tensões internas e deformação plástica exercem efeitos no desempenho dos componentes. As técnicas de tratamento térmico podem ser desenvolvidas à custa de experimentos e materiais, mas, também, através de simulação numérica o que propiciou avanço na tecnologia de processo de cementação a gás padrão e baixa pressão, ligas, equipamentos e controle [6]. A ocorrência de defeitos no processo de cementação (oxidação, descarbonetação, estruturas não martensíticas, etc.) pode levar à redução da dureza na camada superficial do material, bem como o estabelecimento de tensões residuais de tração levando à redução da resistência à fadiga do componente.

O processo de cementação é difusional, descrito pela segunda lei de Fick e consiste na introdução de carbono na superfície de uma peça pela sua inserção em meio rico em carbono. Atualmente, questões de custo ditaram a substituição de atmosferas gasosas ricas em propano $\left(\mathrm{C}_{3} \mathrm{H}_{8}\right)$ por gás natural. Devido à sua menor concentração de carbono, o gás natural possui menor capacidade de carbonetação que o propano, ocasionando aumento dos tempos de tratamento em processos de cementação.

\footnotetext{
* Contribuição técnica ao $69^{\circ}$ Congresso Anual da ABM - Internacional e ao 14ํㅡㄹ ENEMET - Encontro Nacional de Estudantes de Engenharia Metalúrgica, de Materiais e de Minas, 21 a 25 de julho de 2014, São Paulo, SP, Brasil.
} 


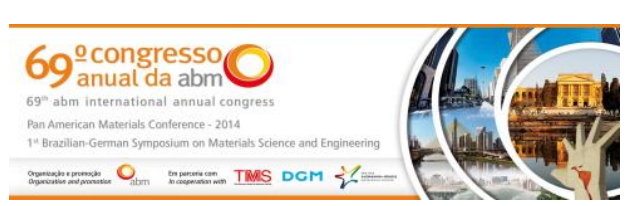

zona) dos fornos de tratamento térmico, promovendo a elevação do potencial de carbono. A adição de etanol eliminou o oxigênio residual que penetrou no forno através da porta de alimentação no carregamento. $O$ volume de etanol adicionado variou entre 1,2 a 1,8 I/h nessas câmaras. As peças permaneceram na $1^{\underline{a}}$ e $2^{\underline{a}}$ zonas durante 140 minutos nas temperaturas de 870,890 e $930^{\circ} \mathrm{C}$ e, em seguida, deslocaram-se automaticamente até a $3^{\text {a }}$ zona de difusão, a temperatura de $830^{\circ} \mathrm{C}$ onde permaneceram por 50 minutos com posterior resfriamento em óleo. Após o tratamento térmico, foi feita a limpeza das peças através de jateamento de água aquecida a $50^{\circ} \mathrm{C}$ com desengraxante alcalino a $3 \%$. Em seguida, as peças passaram pelo processo de revenimento na temperatura de $150^{\circ} \mathrm{C}$ por 90 minutos. O teor de $\mathrm{CO}$ e $\mathrm{CO}_{2}$ em na zona de cementação do forno, determinado como função da vazão de etanol é apresentado na Figura 1.

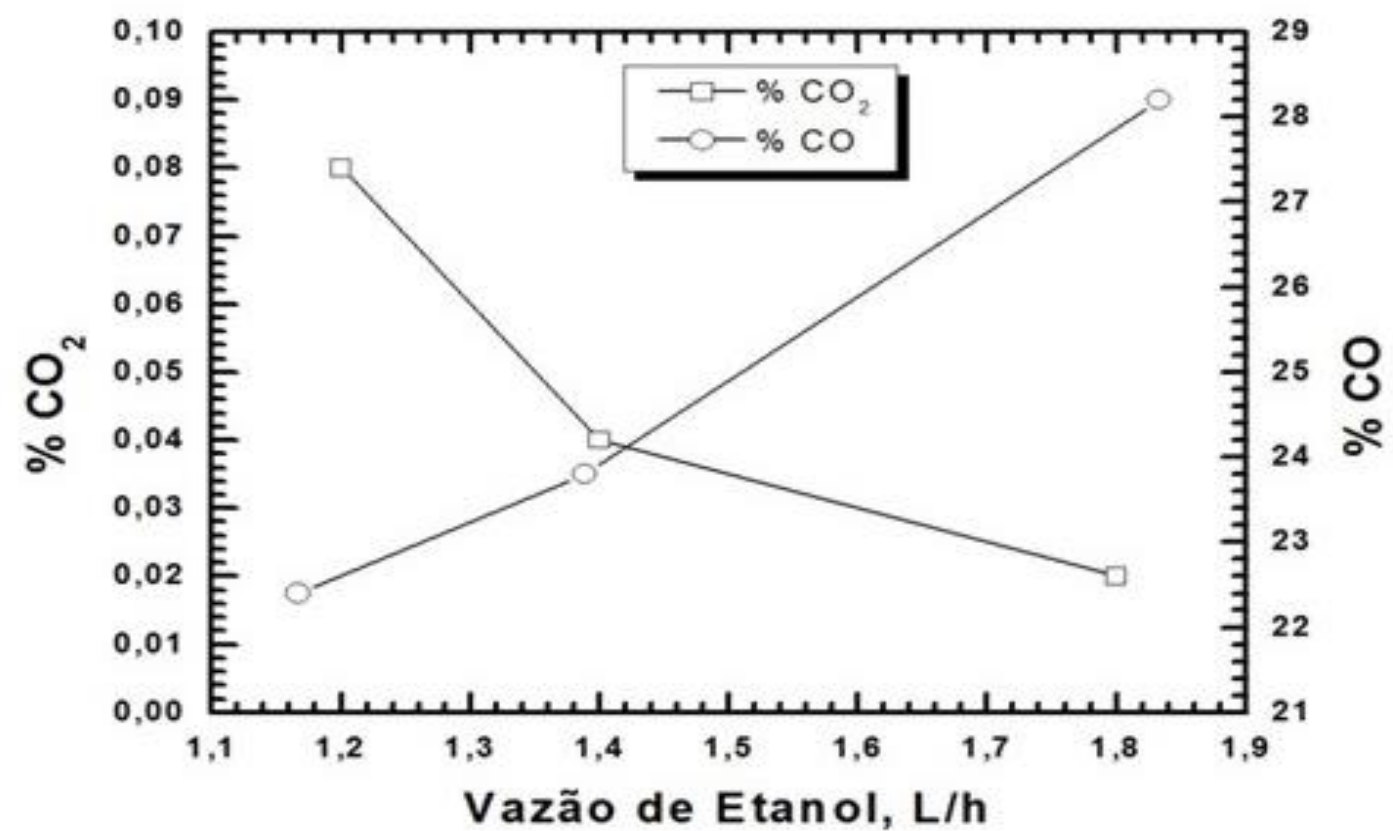

Figura 1. Composição química da atmosfera do forno na zona de cementação em função da vazão de etanol utilizada.

\subsection{Análise por Difração de Raios-X}

As frações volumétricas de austenita retida e martensita a podem ser quantificadas por difração de raios-X (DRX) comparação direta (Sugimoto; Usui; Kobayashi; Hashimoto, 1992). Esse método utiliza a integração dos picos de difração mais intensos dos planos da austenita caracterizados por (111), (200), (220) e, também, da martensita a caracteizados por (110), (200), (211) e (220). No presente trabalho, a fração relativa de cada fase presente foi determinada pelo método Rietveld, no software MAUD versão 2.26 [7]. A análise foi realizada com uma fonte laboratorial de

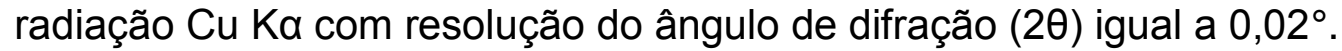

\footnotetext{
* Contribuição técnica ao $69^{\circ}$ Congresso Anual da ABM - Internacional e ao 14ํㅡㄹ ENEMET - Encontro Nacional de Estudantes de Engenharia Metalúrgica, de Materiais e de Minas, 21 a 25 de julho de 2014, São Paulo, SP, Brasil.
} 


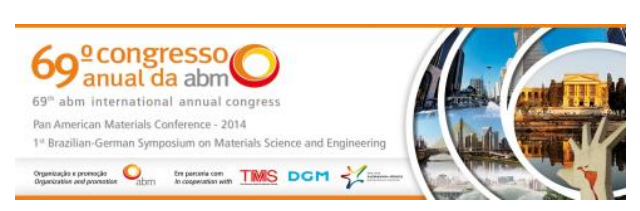

\section{RESULTADOS E DISCUSSÃO}

\subsection{Microestrutura}

Na Figura 2(a), 2(b) e 2(c) é apresentada a microestrutura dos aços submetidos a tratamento de cementação às temperaturas de 870,890 e $930^{\circ} \mathrm{C}$, respectivamente. Observa-se os contornos de grão austeníticos revelados pelo ataque. Utilizando-se o método de Hilliard foi obtido o tamanho de grão médio, respectivamente, $20+-2 \mu \mathrm{m}$; $22+-3 \mu \mathrm{m}$ e 38,5+-4 $\mu \mathrm{m}$. A redução desse tamanho de grão pode ser obtida com a adição de nióbio na faix de 0,04 a $0,08 \%$ ou através de dupla têmpera [8,9]. Há três modos mais efetivos para melhorar a resistência à fadiga de engrenagens cementadas quais sejam, acréscimo nas tensões compressivas superficiais, refinamento do tamanho de grão austenítico e minimização da oxidação intergranular nos contornos de grão austeníticos durante a cementação [10]. Morris et al. [11] mostraram que, no caso de aços martensíticos, deve-se conhecer o tamanho dos blocos ou pacotes cristalograficamente coerentes como os parâmetros que afetam a resistência. O refino de grão austenítico reduz o comprimento as ripas, então o tamanho dos blocos reduz [11].


Figura 2. Contornos de grão austeníticos revelados por ataque com TEPOL para as amostras cementadas a (a) $870^{\circ} \mathrm{C}$, (b) $890^{\circ} \mathrm{C}$ e $930^{\circ} \mathrm{C}$.

Na Figura 3 é apresentada a superfície a da engrenagem na região do diâmetro primitivo com a presença de oxidação intergranular. A redução da oxidação intergranular pode ser devida a queima do oxigênio pela maior presença de carbono

\footnotetext{
* Contribuição técnica ao $69^{\circ}$ Congresso Anual da ABM - Internacional e ao 14ํㅡㄹ ENEMET - Encontro Nacional de Estudantes de Engenharia Metalúrgica, de Materiais e de Minas, 21 a 25 de julho de 2014, São Paulo, SP, Brasil.
} 


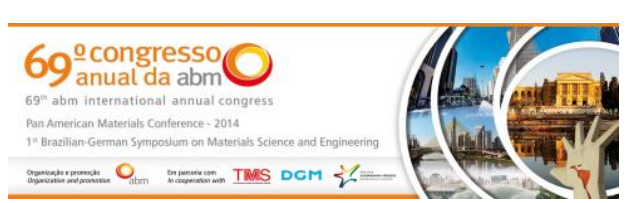

ocasionada da decomposição do álcool. Essa vantagem na adição do álcool é importante, uma vez que a oxidação intergranular pode reduzir a resistência à fadiga do componente [12].

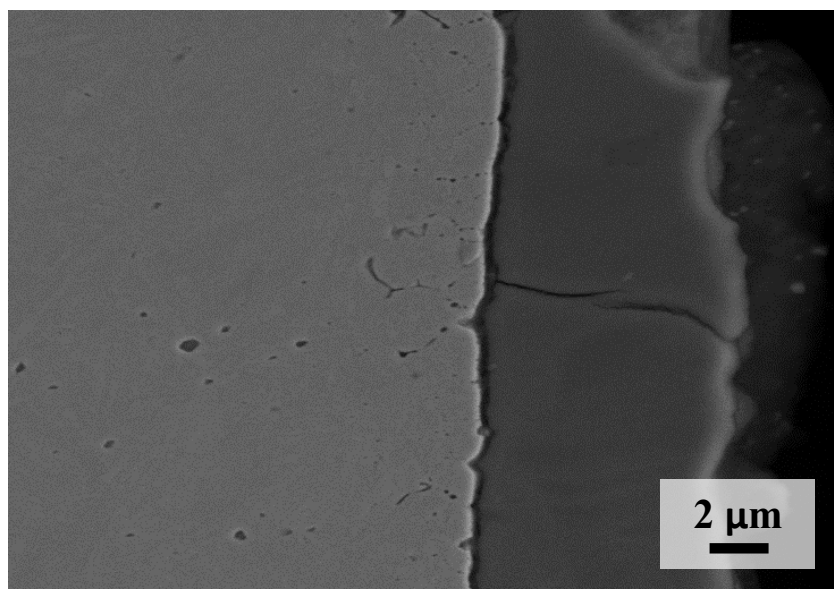

Figura 3. Amostra cementada a $930^{\circ} \mathrm{C}$ observada no FEG evidenciando oxidação intergranular em intensidade reduzida.

\subsection{Análise Quantitativa de Fases}

Os resultados das análises de difração de raios-X efetuadas nas amostras cementadas a 870,890 e $930^{\circ} \mathrm{C}$ são apresentados nas Figuras 4, 5 e 6, respectivamente. A fração das fases (em \% peso) calculadas para as peças cementadas a $870{ }^{\circ} \mathrm{C}$ foi de $82,0 \%$ de martensita e $18,0 \%$ de austenita com erro de $0,86 \%$. Para as peças cementadas a $890^{\circ} \mathrm{C}$ encontrou-se $96,1 \%$ de martensita e $3,9 \%$ de austenita com erro de $0,32 \%$ enquanto que para as amostras tratadas a $930^{\circ} \mathrm{C}$ as frações detectadas foram $77,5 \%$ de martensita e $22,5 \%$ de austenita com erro de $0,90 \%$. Não se observou uma variação consistente da fração de austenita retida com respeito à temperatura de cementação utilizada.

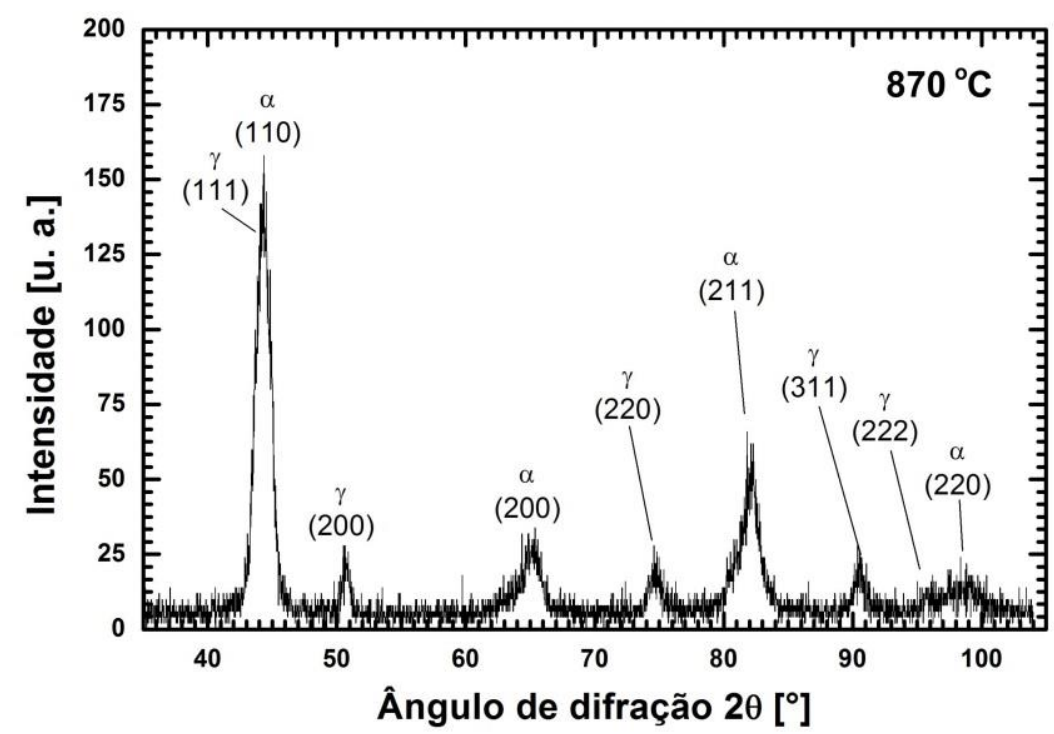

Figura 4. Difractograma para a amostra de aço DIN $17 \mathrm{NiCrMo5}$ submetida a tratamento de cementação a $870^{\circ} \mathrm{C}$.

* Contribuição técnica ao 69 Congresso Anual da ABM - Internacional e ao 14ํㅡㄹ ENEMET - Encontro Nacional de Estudantes de Engenharia Metalúrgica, de Materiais e de Minas, 21 a 25 de julho de 2014, São Paulo, SP, Brasil. 

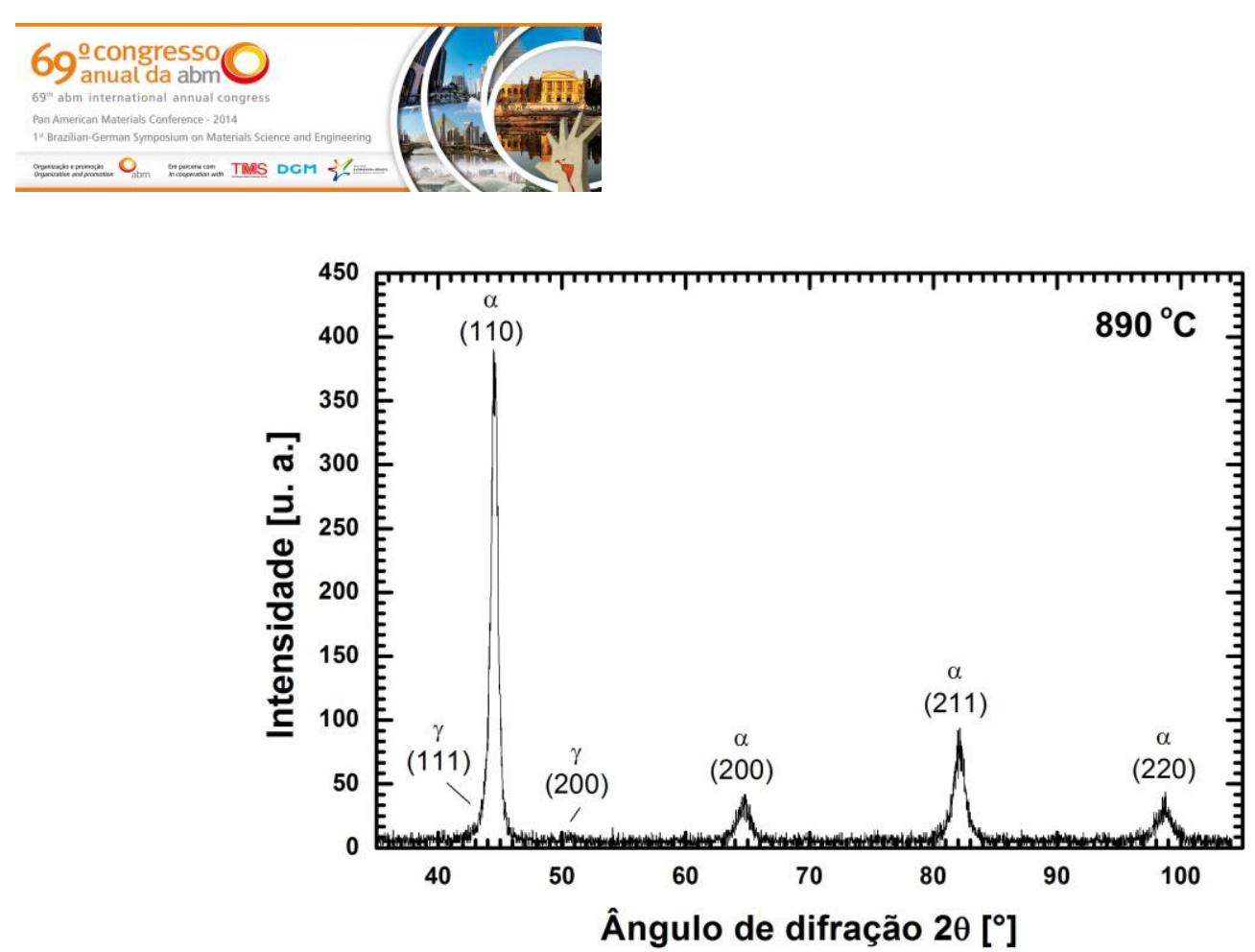

Figura 5. Difractograma para a amostra de aço DIN $17 \mathrm{NiCrMo5}$ submetida a tratamento de cementação a $890^{\circ} \mathrm{C}$.

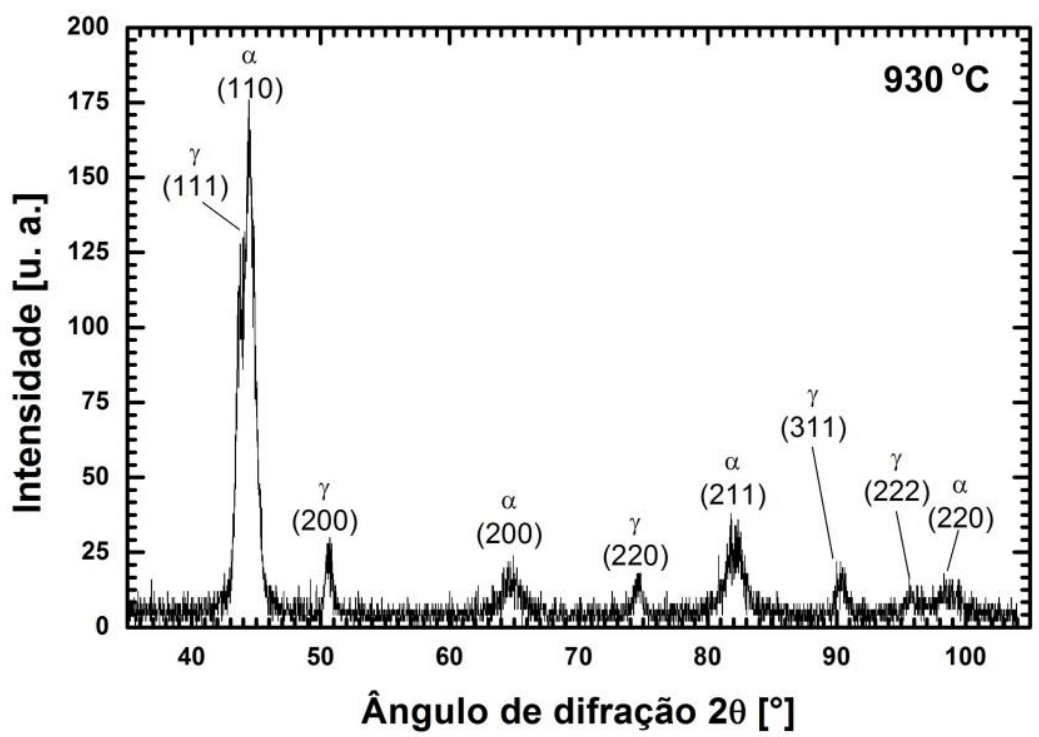

Figura 6. Difractograma para a amostra de aço DIN $17 \mathrm{NiCrMo5}$ submetida a tratamento de cementação a $930^{\circ} \mathrm{C}$.

\subsection{Análise do Processo de Cementação}

Na Figura 7 é apresentada a evolução do teor de carbono após cementação para engrenagens tratadas nas temperaturas de 870,890 e $930^{\circ} \mathrm{C}$. As curvas apresentadas na Figura 7 representam, para cada temperatura de tratamento, a média de 3 valores para a concentração de carbono. Para a temperatura de tratamento de $870^{\circ} \mathrm{C}$, observa-se que o teor de carbono atingido na superfície situou-se em torno de $0,7 \%$. Esse teor de carbono se mantém até profundidades de $0,15 \mathrm{~mm}$, e a partir daí, decresce até a profundidade de $0,75 \mathrm{~mm}$ quando então atinge o valor da composição química nominal do aço. Ao se aumentar a temperatura de austenitização para $890^{\circ} \mathrm{C}$, reduziu-se o potencial de carbono da atmosfera preservando o tempo de resfriamento entre as temperaturas de 890 e $840^{\circ} \mathrm{C}$ o que ocasionou a queda do teor de carbono da superfície e, também, o perfil de carbono

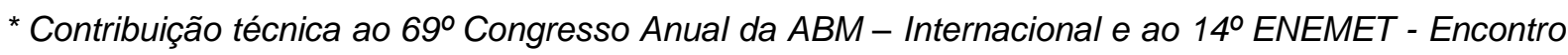
Nacional de Estudantes de Engenharia Metalúrgica, de Materiais e de Minas, 21 a 25 de julho de 2014, São Paulo, SP, Brasil. 

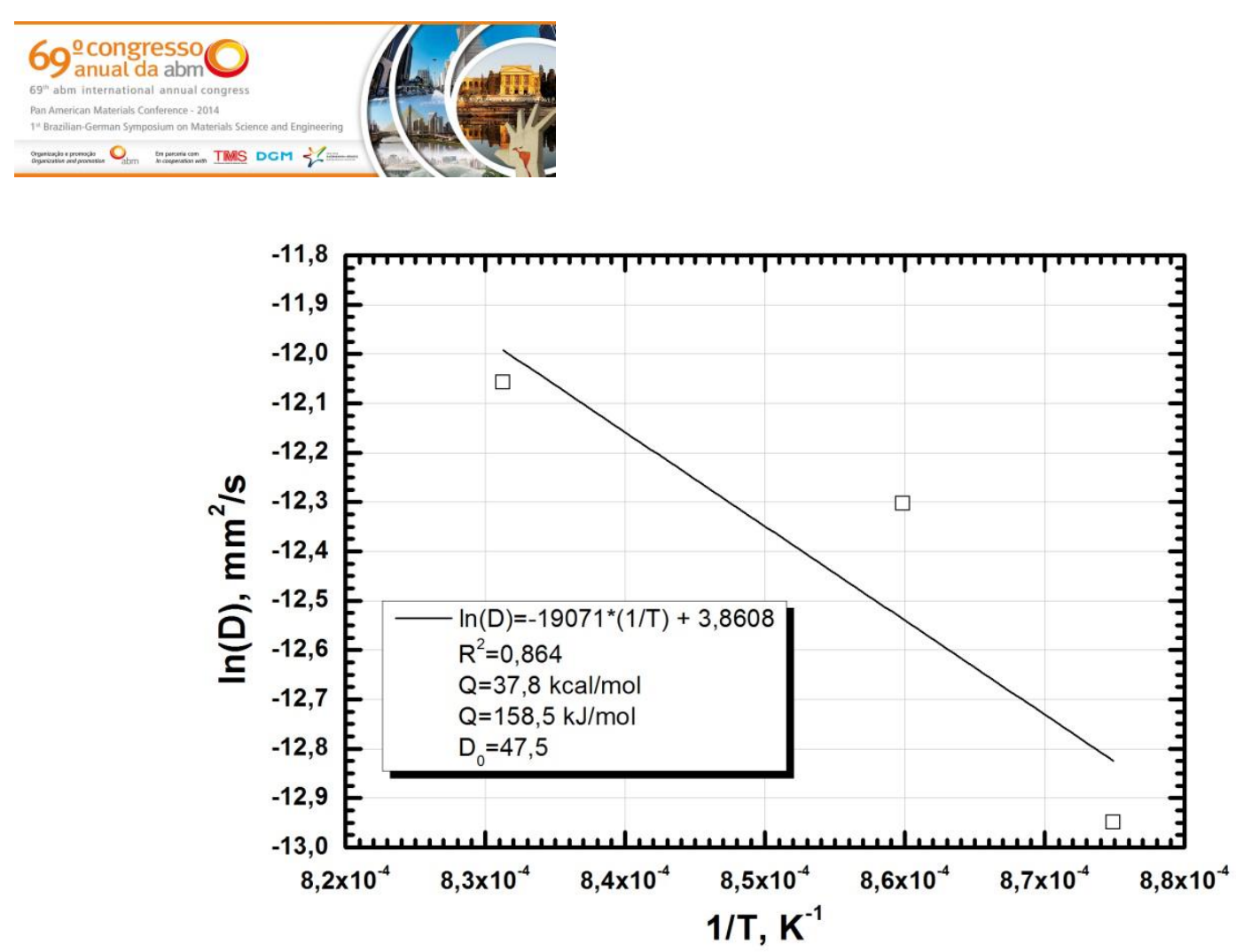

Figura 8. Cálculo da energia de ativação para a difusão de carbono na austenita.

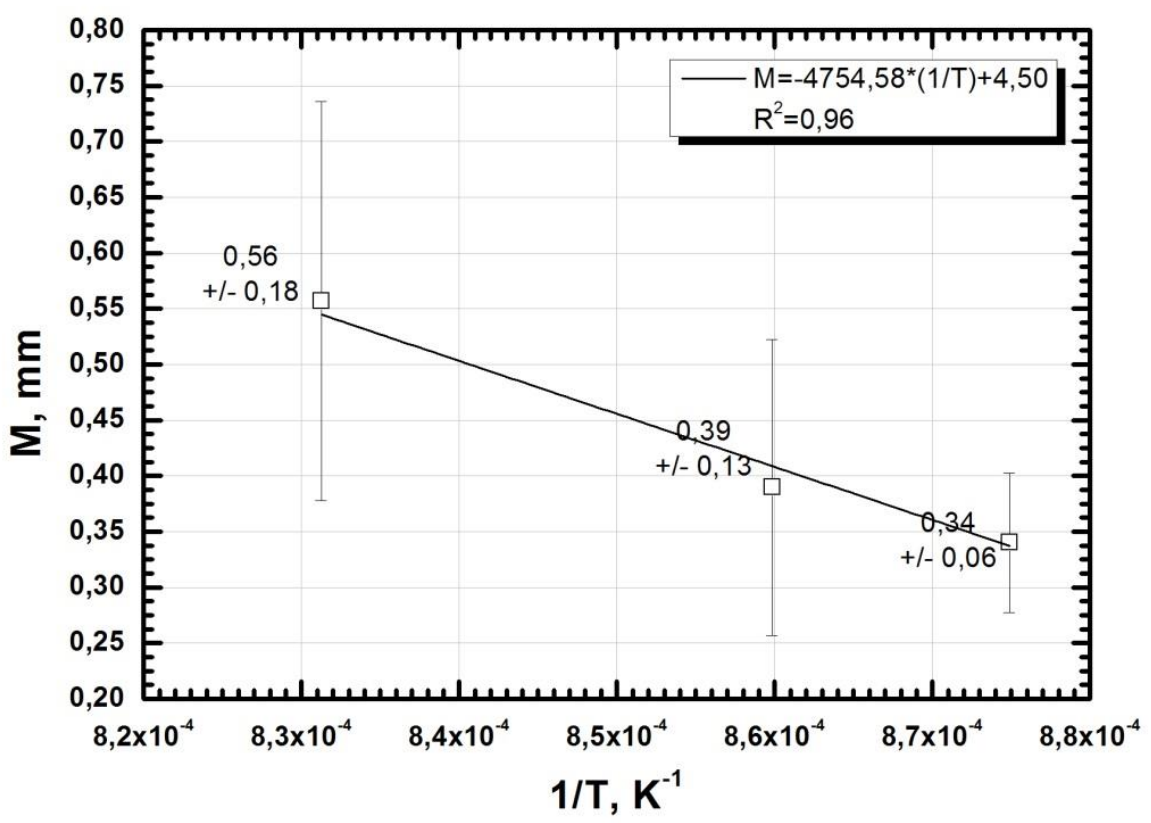

Figura 9. Cálculo da constante $M$ versus 1/T, conforme Equação (1).

\section{CONCLUSÃO}

No presente trabalho engrenagens de DIN $17 \mathrm{NiCrMo5}$ foram submetidas a tratamento termoquímico de cementação em atmosfera de gás natural e etanol nas temperaturas de 870,890 e $930^{\circ} \mathrm{C}$. A adição de etanol ao gás natural levou ao aumento do teor de $\mathrm{CO}$ da atmosfera dos fornos de tratamento, o que indica a possibilidade de aumento da velocidade do processo no estágio de enriquecimento de carbono nas peças. Após o processo de cementação, as amostras foram temperadas e revenidas. A análise de fases indicou presença de austenita retida em todas as amostras tratadas, com tamanho médio de grão de $20 \pm 2 \mu \mathrm{m}$. A variação da concentração de carbono em profundidade das amostras foi determinada

\footnotetext{
* Contribuição técnica ao 69ำ Congresso Anual da ABM - Internacional e ao 14ํㅡㄹ ENEMET - Encontro Nacional de Estudantes de Engenharia Metalúrgica, de Materiais e de Minas, 21 a 25 de julho de 2014, São Paulo, SP, Brasil.
} 
